\title{
Guerra y fiscalidad en el tránsito del Virreinato a la República: Nueva Granada, 1796-1821
}

\author{
por Decsi Arévalo Hernández
}

\begin{abstract}
A preferential issue in the fiscal historiography is to determine the effect of taxes on the economic activity. In the period of transition between the colonial rule and the formation of the Republic of New Granada, however, the relationship between the political regime and taxation is more important, given that the economic progress was delayed by the need to defend the territory. In this perspective the purpose of this paper is to contrast the development of the Treasury with the evolution of political conflicts. There will be differentiated three periods: a first one encompassing the war with France and England, a second one comprising the construction of the Republic between 1810 and 1815, and a third one covering the Spanish reconquest and independence of New Granada. This article traces the interrelationship between the territorial reconfiguration of the State and the organization of the tax system in these periods of war.
\end{abstract}

\section{INTRODUCCIÓN}

El periodo que cubre este artículo está determinado por las condiciones de guerra en que se desenvolvieron las sociedades española y neogranadina. Comienza con la larga guerra entre España y Gran Bretaña, iniciada en 1796 y, con una breve pausa entre 1802 y 1804, finalizada en 1808. A este conflicto le siguió la invasión francesa de la Península, la caída de la Monarquía española y la fragmentación política en España, que duró hasta el regreso de Fernando VII en 1814. En ese intermedio se presentan el proceso de independencia hispanoamericana y, finalmente, la reconquista española. El periodo termina con el restablecimiento del gobierno republicano y la confor- 
mación de la Gran Colombia en los antiguos territorios del Virreinato de la Nueva Granada. ${ }^{1}$

En este escenario resulta importante discutir las relaciones que se tejen entre política, economía y finanzas públicas. Si bien un tema privilegiado en la historiografía fiscal es determinar el efecto de los impuestos sobre la actividad económica, en el periodo objeto de estudio es más relevante la relación entre régimen político y fiscalidad, toda vez que el progreso económico quedó postergado ante la necesidad de la defensa del territorio. En esta perspectiva el propósito de este artículo es contrastar el desenvolvimiento de la hacienda con la evolución de los conflictos políticos. Para ello se diferencian tres periodos: el primero correspondiente a la guerra entre Francia e Inglaterra, el segundo a la construcción de la República entre 1810 y 1815 , y el tercero a la reconquista española y la independencia neogranadina.

Es preciso subrayar que el análisis que se presenta en este artículo no hace referencia a todo el territorio del Virreinato de la Nueva Granada, sino sólo a la Audiencia de Santafé. Además de esta entidad, al Virreinato pertenecían la Audiencia de Quito y la Capitanía General de Venezuela (ver gráfico 1). Aun cuando las provincias de Panamá y Veraguas se consideraban parte del territorio de la Audiencia de Santafé, en la práctica no había una directa relación administrativa, de modo que permanecieron al margen de la dinámica de la Audiencia de Santafé y en el tiempo del movimiento independentista estuvieron bajo el control de los españoles.

1 El Virreinato de la Nueva Granada se creó en 1719, pero se suprimió cinco años después, luego se restableció en 1739 y duró hasta la independencia de la Nueva Granada. 
Gráfico 1: Mapa de la Audiencia de Santafé en 1810

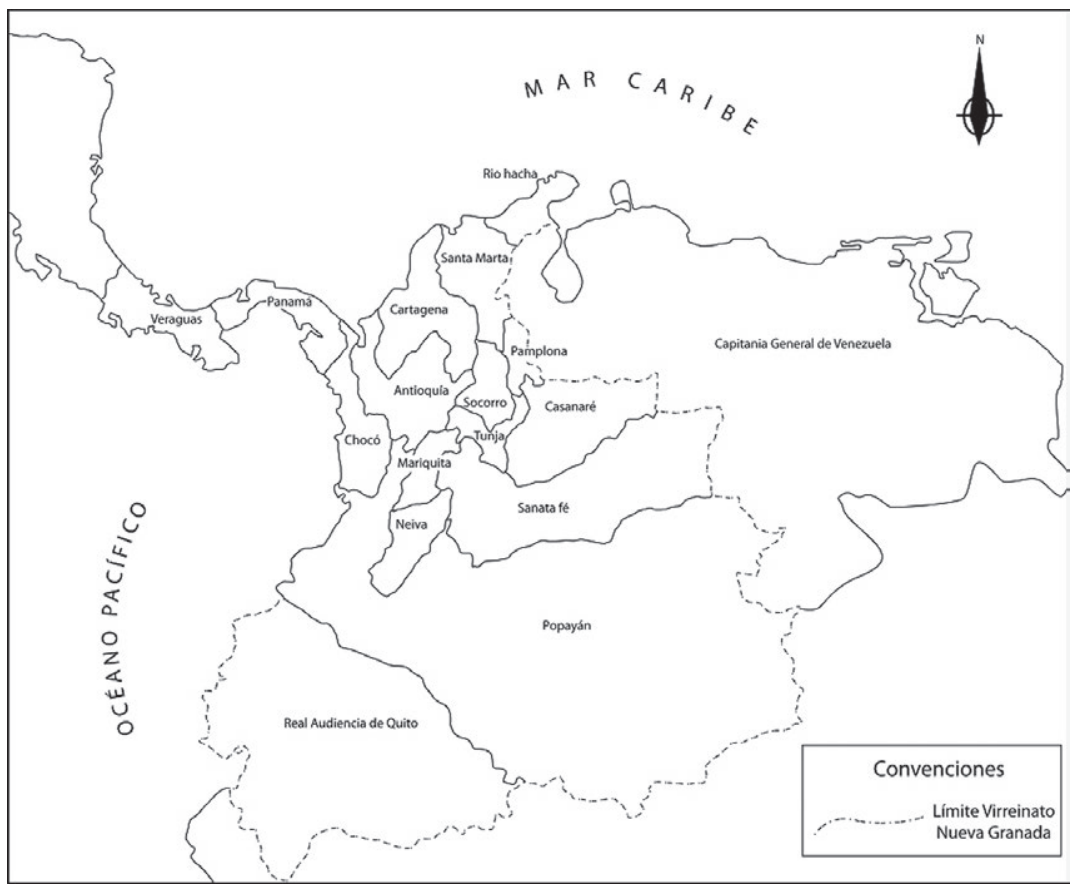

Fuente: Guillermo Sosa, Representación e independencia 1810-1816 (Bogotá 2006), p. 182.

\section{LA RELACIÓN ENTRE POLÍTICA Y FISCALIDAD}

Dos grandes vertientes teóricas se pueden identificar al abordar los temas fiscales: por un lado el liberalismo y por el otro los enfoques holistas. En la primera vertiente predomina la visión individualista en la que las organizaciones tanto política como económica dependen de la unión de voluntades. Con este enfoque se prescribe que el sistema impositivo es justo en la medida en que cada cual contribuya de acuerdo a sus respectivas capacidades y en proporción a los ingresos que disfruta bajo la protección estatal. Por su parte, los gastos son aquellos que cobijan a todos los ciudadanos sin distingo de condición, raza o religión. Esta perspectiva clásica de los impuestos va a ser desarrollada progresivamente para elucidar el grado de afectación que han podido tener los impuestos sobre la actividad económica, te- 
niendo especial cuidado en definir los problemas de asignación de recursos que puede estar generando. ${ }^{2}$

Los enfoques institucionalistas más recientes han privilegiado el recurso a la acción colectiva y a la elección social como modelos de interpretación para el problema fiscal. De esta manera, las preguntas tienen que ver - entre otras cosas - con el grado de participación de los individuos en la definición de los impuestos y de los gastos, las formas de colusión, así como el intercambio entre la racionalidad gubernamental y la individual. Este tipo de perspectivas implica partir de una base social en la cual cada uno de los individuos puede tener igual grado de participación dentro de la sociedad y concebir que la interacción social procura el bienestar general, entendiendo además que este es compartido por la colectividad. Sin embargo, tal forma de conceptualización da pie a preguntarse cuál es su alcance para ser aplicado en una sociedad y una economía en las que no hay participación política ni espacio para la discusión del impuesto.

Desde otro frente, en la perspectiva histórica legada por el marxismo se pueden encontrar pistas que permitan estudiar ese tipo de sociedades. Al hablar del moderno sistema tributario, Marx señala que viene aparejado con la deuda pública, propia del mercantilismo (periodo de transición del feudalismo al capitalismo), que expande el mercado mundial por medio de las guerras comerciales. Nuevos empréstitos significan nuevos impuestos para sufragar los gastos y los intereses de los empréstitos concedidos al Estado. ${ }^{3}$

Esta articulación de lo político y lo económico en la fiscalidad se puede resumir en que en la esfera de lo político e institucional se aprecia como el Estado convalida su actividad financiera mediante el uso del poder político, que se sustenta en las instituciones desplegadas para cumplir con esta finalidad. En el terreno de lo económico la acción del Estado se inscribe en un conjunto de actividades económicas, pero con la peculiaridad que - vía la política económica, entre ellas la fiscal - puede modificar los ritmos de acumulación.

2 Esta idea es desarrollada en Decsi Arévalo/Óscar Rodríguez Salazar, "La fiscalidad bajo un régimen de dominación colonial. El caso de la Caja Real de Cartagena 1738-1802": Anuario Colombiano de Historia Social y de la Cultura 35 (2009), pp. 19-64.

3 Carlos Marx, El Capital, tomo I (México, D.F. 1966), p. 641. 
Además, la hacienda pública expresa la interdependencia de los grupos sociales y las relaciones de fuerza que reinan dentro de una sociedad. Esto se hace explícito cuando ante el Congreso se presentan los presupuestos o se tramita una reforma tributaria: los grupos sociales entran en pugna, con el fin de ser beneficiarios del gasto público o no ser afectados por el sistema tributario. Así pretenden obtener exenciones o deducciones y evitar los controles a la evasión y la elusión. Por ello, el impuesto es un elemento estructurante de la matriz social: participa de la definición de múltiples relaciones sociales que estructuran las sociedades nacionales.

Esa dinámica de interrelación también se encuentra en Norbert Elias, quien enfatiza en las redes de dependencia recíproca que hacen que cada acción individual dependa de toda una serie de otras, modificando a su turno las formas de relación social. La noción de interdependencia aplicada a las unidades sociales en competencia para la obtención de recursos de oportunidades sociales conduce a la monopolización, mecanismo válido también para el análisis de las prácticas políticas y de los comportamientos individuales. ${ }^{4} \mathrm{El}$ proceso de monopolización de la violencia por parte del Estado aparece en el ascenso de la sociedad cortesana y está acompañado de la centralización creciente del poder estatal mediante el uso de dos mecanismos: los impuestos y las fuerzas del Ejército y la policía. El doble monopolio estatal, militar y fiscal, no es más que la expresión socio-espacial de las interdependencias motrices de este proceso de monopolización. ${ }^{5}$

\section{FISCALIDAD COLONIAL Y GUERRAS COMERCIALES IMPERIALES}

Con la creación del Virreinato se puso en marcha el proceso reformador de los Borbones, que buscaba transformar el sistema mercantil colonial de modo que las colonias no sólo fueran la fuente de recursos provistos por la naturaleza, sino que también fueran importantes consumidoras de productos españoles. En el marco de esta pretensión se

4 "El individuo o, dicho con mayor exactitud, aquello que lo refiere el concepto actual de individuo, sigue entendiéndose como algo que existe 'fuera' de la sociedad. A su vez, aquello a lo que se refiere el concepto de sociedad se muestra como algo que existe fuera y más allá del individuo". Norbert Elias, El proceso de la civilización: investigaciones sociogenéticas y psicogenéticas (México, D.F. 1987), p. 35.

5 Ibidem, p. 54. 
eliminó el monopolio de Cádiz, se creó el régimen de navíos sueltos y se ampliaron los permisos comerciales. A esta política se intentó adicionar el fomento de la producción local, así como la homogenización y centralización fiscal. Sin embargo, esta dinámica produjo escasos frutos, no sólo en razón de las dificultades administrativas y la fuerza de los poderes locales, sino también por las condiciones de guerra.

La relación entre fiscalidad y guerra se puede observar en dos caminos: de una parte en los efectos que la declaración de guerra generó sobre el comercio y éste a su vez sobre el recaudo de impuestos; y de otra parte en la distribución de gasto, pues la guerra demandó mayores recursos para responder a la confrontación armada. Este proceso es bastante evidente en las guerras imperiales de finales del periodo colonial y puede ser ilustrado con la guerra entre España e Inglaterra a partir de 1796.

Terminada la guerra hispano-francesa de 1793-1795, los dos países firmaron el tratado de San Ildefonso de 1796, a través del cual unieron sus fuerzas para luchar contra Gran Bretaña. Un elemento interesante de la declaración de esta nueva guerra y del acuerdo de San Ildefonso es que España pretendía participar en el conflicto sin recibir los perjuicios del daño comercial que implicaba el enfrentamiento, es decir, suponía que las potencias en conflicto aceptarían su postura de neutralidad comercial. Esta pretensión dio lugar a la política de comercio neutral que por sus intermitencias generó trastornos significativos en el comercio de las colonias. ${ }^{6}$

Dos problemas se sumaron a las variaciones en el comercio neutral: el comercio privilegiado y el contrabando. En el caso de la Audiencia de Santafé buena parte de las licencias de exportación se entregaban a comerciantes de España residentes en Cartagena. Dicho otorgamiento, como en la experiencia del palo de Brasil, podía continuar aun después de que el Gobierno virreinal se arrogó el monopolio

${ }^{6}$ Los súbditos españoles, peninsulares o americanos, pudieron utilizar barcos de países neutrales que salieran de puertos españoles o neutrales, comerciar con puertos americanos habilitados, con mercancías españolas y extranjeras, y mandar productos americanos a los puertos españoles. Ver Cristina Mazzeo, "Comercio 'neutral' y comercio 'privilegiado' en el contexto de la guerra de España con Inglaterra y con Francia 1796-1815": II Congreso Peruano de historia marítima y naval (Lima 1998), publicado en línea: www.derroteros.perucultural.org.pe/textos/neutral.doc . Según las disposiciones de la Corona, el comercio neutral estuvo activo entre 1797 y 1799, entre mayo y diciembre de 1801 y luego en 1804 . 
sobre la exportación. ${ }^{7}$ Por su parte, el contrabando se constituyó en uno de los argumentos del virrey Mendinueta (1796-1803) para retrasar la aplicación de las medidas de comercio neutral, pues en su opinión reactivarían el contrabando. Esta posición dio lugar a una controversia, en particular con el gobernador de Cartagena, quien veía en la medida la ocasión no sólo de promover el comercio, sino también de acrecentar los recursos de aduanas. ${ }^{8}$

La valoración del impacto del comercio neutral sobre el comercio es un asunto complicado, no sólo por la intermitencia de la medida, sino también porque cuando se suprime queda una ventanilla para que dé pie a su aplicación, esto es que el comercio neutral podría seguirse aplicando "en los casos de urgente necesidad". En Nueva Granada, como en otras regiones, la interpretación de las normas propició la continuación, en algunos casos - es decir, para algunos comerciantes -, del tráfico de mercancías en barcos de naciones neutrales, el intercambio de mercancías con otros puertos americanos y la variación en el cobro de las tarifas de aduanas e impuestos al comercio. ${ }^{9}$ Otros comerciantes, en cambio, sufrieron los rigores de las normas, y tras reiterados fracasos comerciales -, mercancías almacenadas sin poder ser exportadas, apresamiento de barcos por los corsarios, entre otros - acumularon grandes pérdidas.

Como se ha determinado en otros estudios el sistema impositivo colonial tenía dos vertientes: una derivada de la sociedad estamental y otra de la actividad económica. ${ }^{10}$ En la primera de ellas se encuentran impuestos a los indios, a la burocracia, al clero y a la nobleza. Respecto a la actividad económica se encuentra una amplia gama de impuestos que cubrían distintas formas de percepción de rentas, entre ellas las rentas estancadas (tabaco, aguardiente, naipes, papel sellado y pólvora; los impuestos a la tenencia y explotación de la tierra, al comercio y la minería; las regalías - maderas preciosas por ejemplo);

7 Jesús Bohórquez, "Más para entretener la miseria que despertar la codicia: los frutos del comercio y los mercados imperiales durante el nacimiento del liberalismo. Nueva Granada, 1780-1810": Anuario Colombiano de Historia Social y de la Cultura 36 (2009), pp. 17-53.

8 John Fisher, El comercio entre España e Hispanoamérica, 1797-1820 (Madrid 1993), p. 52.

9 Bohórquez, "Más para entretener la miseria" (nota 7).

10 Óscar Rodríguez Salazar, "La Caja Real de Popayán": Anuario Colombiano de Historia Social y de la Cultura 15 (1987), pp.7-30, aquí: pp. 10 y ss. 
pero también se obtenía ingresos por capturas de contrabando, expropiaciones, multas, etc. Desde la perspectiva del gasto, unos rubros corresponden a transferencias a la Corona, otros a aplicaciones derivadas del patronato, otros a la administración, incluida la fiscal, y otros más a la defensa.

Cuatro son las Cajas Reales principales que existían en el territorio de la Nueva Granada: Santafé, localizada en la capital del Virreinato; Popayán, situada en el sur; Santa Marta en el norte sobre la costa del Caribe, la caja más pequeña; y Cartagena que operaba como principal puerto para el comercio exterior. $\mathrm{Al}$ observar los ingresos percibidos por el Virreinato de la Nueva Granada a través de las Cajas Reales se encuentra una clara relación con la economía regional y el interés por el control territorial. La principal fuente de ingresos en la Caja de Santafé eran los recursos de sus cajas sufragantes, es decir, fiscalmente Santafé excedía sus límites geográfico-políticos. El siguiente rubro de importancia lo constituían el tributo indígena y las rentas estancadas, en especial tabaco y aguardiente; en los siguientes renglones se encuentra una gran colección de impuestos con aportes comparativamente bajos. La Caja de Popayán, que equivalía a cerca del $25 \%$ de la de Santafé, dependía de la alcabala, las rentas estancadas y el tributo indígena, mientras que los demás rubros aportaban muy poco individualmente. La Caja de Santa Marta alcanzaba a constituir el 5\% de la de Santafé y recibía una muy exigua contribución de sus cajas sufragantes.

La Caja Real de Cartagena era la que administraba un mayor volumen de recursos - casi el doble de Santafé. Sin embargo, era una caja que funcionaba a través de las transferencias que recibía del resto de las cajas de la Audiencia de Santafé e incluso de la Audiencia de Quito, enviadas para fortificación, situado y asignaciones de España. La posición de Cartagena como puerto principal del Virreinato implicaba que la caja percibía los impuestos al comercio exterior, pero ejecutaba el gasto en defensa. Respecto al comercio exterior existía un gran número de impuestos: aduanas, armada de barlovento, avería, salida de frutos, almojarifazgo, almirantazgo y registro de navíos. Varios de ellos desaparecieron al inicio del siglo XIX. Una parte de estos impuestos tenían como destinación específica la defensa del comercio.

En el periodo de la guerra de España con Inglaterra se aprecia como en los primeros años se manifiesta un descenso de los ingresos, 
pero rápidamente parecen recomponerse, no sólo en el total, sino también en los impuestos de aduanas, pero no así en los otros impuestos (ver gráfico 2).

Gráfico 2: Caja Real de Cartagena.

EVOLUCIÓN DEL TOTAL DE CARGOS Y PARTICIPACIÓN DEL SITUADO

Y DE LOS IMPUESTOS SOBRE EL COMERCIO EXTERNO

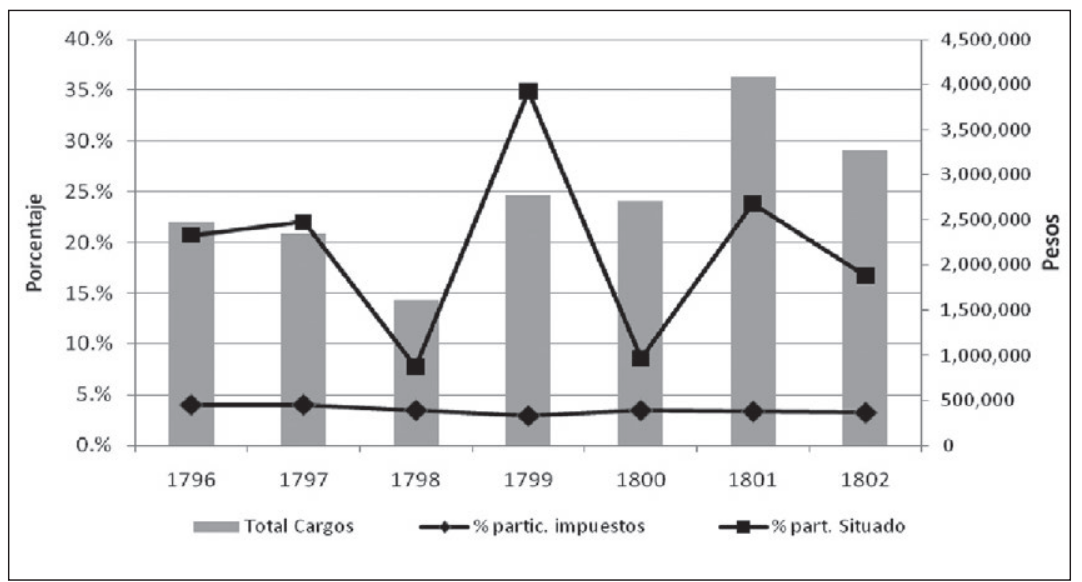

Fuente: Cálculos con base en Archivo General de Indias (en adelante AGI), Audiencia de Santafé, legajos 1099 a 1103.

La tendencia que exhiben los ingresos de la Caja Real de Cartagena induce a pensar que la política de comercio neutral no fue suficiente para compensar los efectos negativos que la guerra generó sobre los tráficos, de modo que tanto el bloqueo comercial como el ataque de los piratas rindieron sus frutos como instrumento de guerra. En la difícil situación de 1798 se conjugaron una caída cercana al 50\% en la renta de aduanas, una dramática disminución del situado remitido de otras cajas y de la renta de tabacos, así como finalmente un bajo nivel en las asignaciones de España.

Con la presencia de corsarios y fragatas inglesas en las rutas de España a América y en el Caribe no sólo se generó un fuerte trastorno al comercio, sino que también se aumentaron los gastos en que debían incurrir los gobiernos virreinales para defender sus territorios. Para la defensa de las colonias hispanoamericanas se había creado un complejo 
sistema de recursos fiscales, que se puede agregar en tres componentes: situado, rentas de la plaza de Cartagena y créditos. Además fue reiterada la demanda de donativos de carácter obligatorio. De otro lado, los gastos en defensa incluían remuneración a la tropa, vestuario y avituallamiento, obras de artillería, fortificación, suministros para marina, utensilios de los cuarteles y hospitales para militares. Como se puede observar en el gráfico 3, los gastos de guerra se elevaron significativamente entre 1797 y 1800 en los puertos de Santa Marta y Cartagena.

Gráfico 3: PARTicipación de los gastos MilitaRes EN El total del gasto, Cajas de Cartagena y Santa Marta (porcentaje)

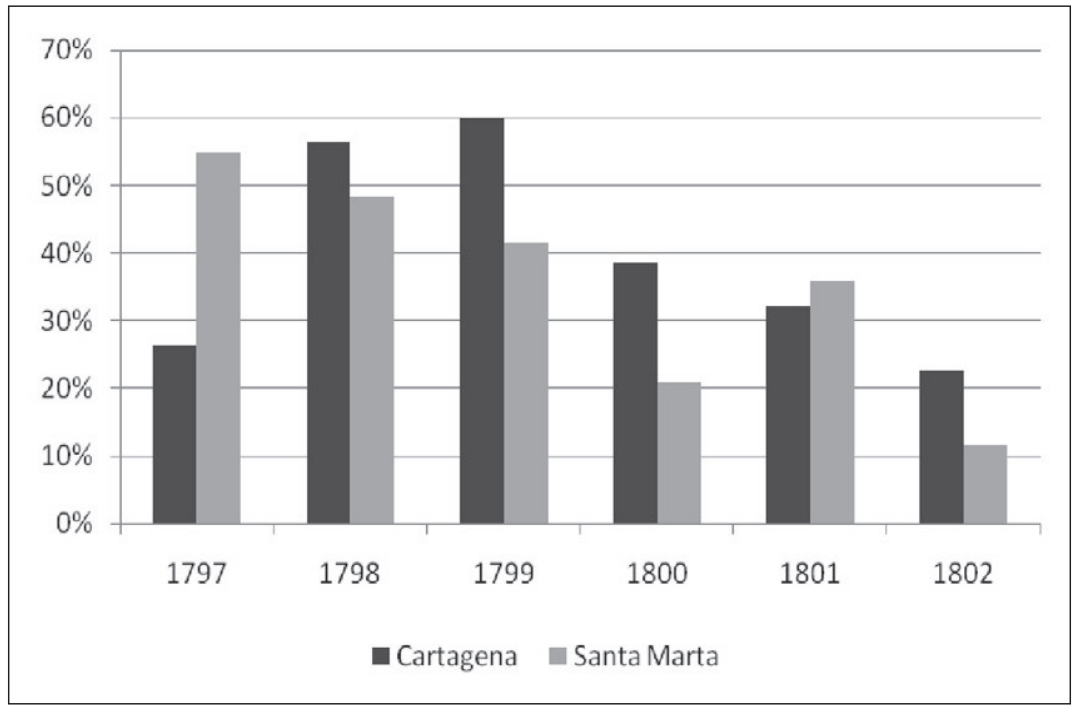

Fuente: Cálculos con base en AGI, Audiencia de Santafé, legajos 1098 a 1103.

En la segunda fase de la guerra entre España e Inglaterra, iniciada a raíz de la captura de barcos españoles por parte de Inglaterra en 1804, los ingresos de la plaza de Cartagena por concepto de aduanas continuaron su descenso, así como los ingresos totales, que entre 1803 y 1805 registraron valores inferiores a los logrados en el bienio 18011802. Por su parte, los gastos de guerra aumentaron de manera considerable, de modo que en 1807 llegaron al $60 \%$ del total de erogaciones contabilizadas en la caja (ver gráfico 4). 
GRÁfico 4: PARTICIPACión DE LOS RAMOS DE ADUANAS, SITUADO Y TABACO EN LOS INGRESOS TOTALES Y PARTICIPACIÓN DEL GASTO MILITAR (PORCENTAJE)
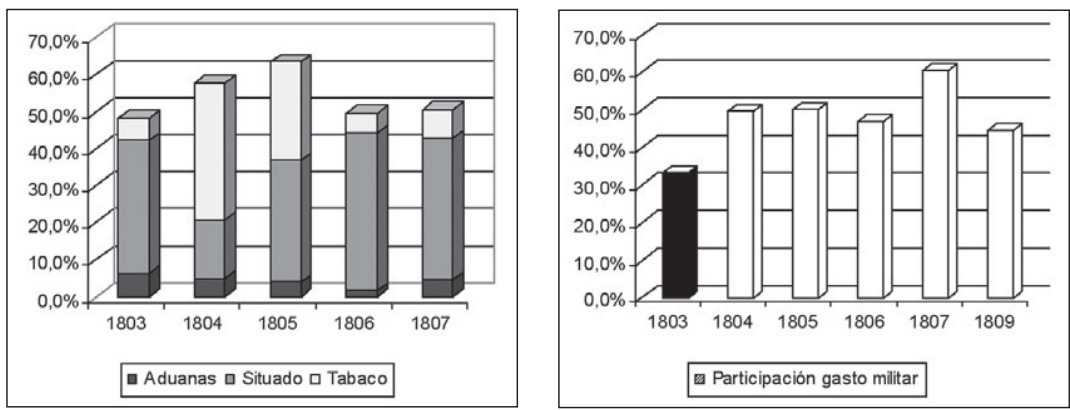

Fuente: AGI, Papeles de Cuba, legajos 727A, 732 y 733A; AGI, Audiencia de Santafé, legajo 1096.

Si las contribuciones en el ramo de aduanas sirven como indicador del ritmo del comercio exterior se puede concluir que entre 1804 y 1807 se manifestó un fuerte obstáculo a su funcionamiento. El descenso generalizado de los ingresos está acompañado de la reducción en las asignaciones de España, que fueron significativas en la primera fase de la guerra y constituían un monto semejante al del situado.

\section{LA FISCALIDAD EN MEDIO DE LA DISCUSIÓN DE LA AUTONOMÍA}

Aun sin finalizar la confrontación con Inglaterra, España se vio abocada a un conflicto con Francia y a una fragmentación interna, derivada de la presencia francesa en territorio español y la captura de Fernando VII. Estos sucesos dieron lugar a la formación de Juntas de Gobierno - que a su vez agenciaron transformaciones en el sistema impositivo - y posteriormente desencadenaron la independencia de las naciones americanas. La ruptura con la dominación colonial en el periodo de 1810 a 1816 brinda otro escenario para analizar la relación entre la fiscalidad y la guerra, en este caso mediada por la búsqueda de autonomía de los dirigentes criollos.

Con la crisis política de España en 1808, la élite criolla hispanoamericana reavivó el debate sobre la participación política de los americanos, los derechos del hombre, la libertad de comercio y el 
sistema impositivo. Con el movimiento comunero de 1781 en la Nueva Granada se inició una serie de movimientos tendientes a buscar una transformación del gobierno en una vertiente liberal de respeto a los derechos del hombre y de participación política. Si bien hasta 1808 se habían generado grupos de estudio y se habían difundido las ideas de los ilustrados, el paso a acciones más contundentes se produjo con posterioridad a la creación de la Junta de Gobierno de Quito en 1808 y su consiguiente liquidación agenciada por el virrey.

No obstante, la instauración de un nuevo gobierno en España motivó la participación más activa de la élite criolla en la discusión política en distintos lugares del Virreinato. En particular, en la Audiencia de Santafé se gestaron movimientos que iniciaron como Juntas, pero que posteriormente declararon la independencia.

De otra parte, desde principios del siglo XIX los "economistas" coloniales (Antonio de Narváez, José Ignacio de Pombo y Pedro Fermín de Vargas) habían llamado la atención sobre la necesidad de modificar las políticas virreinales en aras de generar prosperidad en tierras americanas. En el diagnóstico realizado por estos proto-economistas se destacan las restricciones al comercio libre y a la libre empresa como las principales causantes del atraso. Ignacio de Pombo señaló una serie de incongruencias de la política del Virreinato. En su opinión, si bien los burócratas reales consideraban que mediante el fomento a la agricultura y la minería se podían incentivar las exportaciones e incrementar el mercado interno, no veían que el escaso desarrollo técnico generaba precios no competitivos con el exterior y que, por tanto, era necesario liberar de gravámenes a la actividad económica. Pero las autoridades no tomaron estas decisiones porque consideraban que los recursos eran indispensables para subvencionar las guerras de la Corona. ${ }^{11}$

Sobre asuntos tributarios Joaquín Camacho sostuvo la tesis de la proporcionalidad del impuesto, pues en su opinión para fijarlos se debían tomar en consideración las capacidades de los contribuyentes. Argumentó que los impuestos de tasas fijas, o de capitación igual y

11 Óscar Rodríguez Salazar, "El pensamiento económico en la formación del estado granadino, 1780-1930": Revista Historia Crítica 2 (1989), pp. 93-110; y 3 (1989), pp. 107-117, aquí: no. 3, p. 108. 
forzosa entre los ciudadanos, no se atenían a criterios de justicia. ${ }^{12}$ Compartiendo la visión fisiocrática de Camacho, Ignacio de Pombo abogó por la supresión del sistema tributario colonial, en el que los estancos, las tasas y trabas a la producción, en las compras y ventas y en la navegación obstaculizaban el progreso del país. Asimismo consideró el tributo indígena como envilecedor y causante de su atraso, ignorancia y miseria. ${ }^{13}$

Este tipo de argumentos se fortaleció con los nefastos resultados que se habían obtenido en el mundo de los negocios, como resultado de la guerra entre España e Inglaterra y las medidas restrictivas adoptadas por la Corona. A los argumentos políticos se sumaron los argumentos económicos para apoyar la creación de gobiernos propios en el antiguo Virreinato. Sin embargo, esta búsqueda de autonomía se convirtió en la fuente de la fragmentación del Virreinato y en causa de guerras entre las provincias que reclamaban su independencia.

El movimiento juntista en la Audiencia de Santafé puso en evidencia las fuertes diferencias respecto a la forma de gobierno. Coexistían en el territorio aquellos fieles a la Regencia, los que aceptaban la autoridad monárquica pero no la Regencia y quienes buscaban la independencia de España. Estas diferencias dejaron una división territorial en provincias leales a la Regencia (Santa Marta, Riohacha y Popayán) y provincias que reconocían la Monarquía pero no la Regencia (el resto). No obstante, en estas últimas no se mantuvo la unidad: algunas ciudades importantes de la provincia adoptaron una postura diferente a la de la cabecera provincial o aprovecharon la ocasión para alcanzar la autonomía. Dos casos son notorios al respecto: el primero es el de Cali en la provincia de Popayán, en donde se desconoció la Regencia, se declaró la autonomía, se aglutinó otras ciudades vecinas como Buga y Cartago, y finalmente se enfrentó con Popayán y Pasto, dos importantes ciudades que quedaron en control de los realistas. El otro caso es el de Mompox, ciudad de la provincia de Cartagena que en agosto de 1810 declaró la independencia de España, lo que a su vez significó la independencia de Cartagena. Este intento autonomista fracasó por la recuperación armada que realizó Cartagena.

12 Rafael Gómez, La revolución granadina de 1810. Ideario de una generación y de una época, 1781-1821 (Bogotá 1982), p. 76.

13 Ibidem, p. 301. 
A esa división hay que agregarle la provocada por la discusión sobre la forma de gobierno dentro de las zonas que se distanciaron de la Regencia, discusión volcada sobre la elección entre federalismo y centralismo, pero que alberga el escollo de la jerarquía entre las regiones. Tanto la declaración de independencia hecha por Santafé como la subsiguiente convocatoria a la conformación de un Congreso de Provincias fueron interpretadas de distinta manera en las otras provincias, particularmente porque finalizado el régimen virreinal se creía desaparecida la jerarquización territorial que con éste se había establecido, de modo que las cabeceras de provincia no tenían razón para obedecer la autoridad de Santafé, pero a su vez los cabildos tampoco debían obedecer a las cabeceras de provincia. ${ }^{14}$

Aunque en 1810 se buscó la unidad a partir de la conformación de las Provincias Unidas, que adoptaron un régimen federalista, bien pronto surgieron las discrepancias, particularmente con la provincia de Santafé - posteriormente denominada Cundinamarca - que promovió la adopción de un gobierno centralista con sede en Santafé. Las diferencias respecto a la forma de gobierno también pueden encontrarse en las constituciones que formularon las distintas provincias. En la Constitución de Cundinamarca (1811) se aceptó la autoridad de Fernando VII y se erigió una monarquía constitucional. En el Acta de las Provincias Unidas no hay mención al carácter monárquico o republicano de la nación, y la constitución de Cartagena (1811) estableció la independencia total. Los distintos tonos en que se establecieron las constituciones muestran las diferencias de opinión en torno al carácter de la nueva organización política.

Frente a esta variedad de formas de gobierno no sorprenden las divergencias en materia fiscal ni los trastornos administrativos. En las constituciones de Cundinamarca y Antioquia se estableció claramente que se continuaría con el régimen fiscal anterior, es decir, con la misma estructura administrativa e impositiva. Otras provincias procedieron a establecer un régimen promotor del libre comercio, suprimiendo las rentas estancadas y el impuesto de sisa, y en otros se dio fin al tributo indígena. Por su parte, el gobierno de las Provincias Unidas no modificó inicialmente la estructura definida en cada provincia y se limitó a establecer el principio que figuraba en todas

${ }^{14}$ Guillermo Sosa, Representación e independencia 1810-1816 (Bogotá 2006), p. 87. 
las constituciones: "conciliar la riqueza del Estado con el mayor alivio de los pueblos". Sin embargo, en el Acta de la Federación se estipuló que le correspondía a la Unión la determinación de los impuestos. ${ }^{15}$

La separación de Cundinamarca de la Unión propició el enfrentamiento armado entre estas dos unidades territoriales, así como un movimiento de cabildos: algunos abandonaron a Cundinamarca y se quedaron con la Unión, pero otros hicieron el movimiento inverso. Esta circunstancia no era sólo una cuestión de adhesiones políticas, sino que también era un asunto de circuitos comerciales, que fueron especialmente complicados en regiones que políticamente estaban con la Unión, pero territorialmente quedaban inmersas en Cundinamarca. Una dificultad importante en la circulación mercantil tuvo que ver con las casas de moneda de Popayán y Santafé, es decir, una del lado realista y otra del republicano, pero no del gobierno de la Unión. La complicación derivó de que las zonas productoras de oro y plata de la zona republicana estaban con la Unión, pero la amonedación quedó en manos de Cundinamarca. ${ }^{16}$

A esta fragmentación también contribuyó la localización de las cajas reales y su organización dependiente. En el régimen colonial la caja de Santafé, que quedó luego en manos de Cundinamarca, recibía, además de sus propios ingresos, los recaudos del total de rentas de unas cajas sufragantes y el saldo de otras. De otro lado, realizaba todo el pago de funcionarios directos de la administración pública (incluso en el periodo 1808-1809 estuvo a cargo de los gastos militares, que tradicionalmente habían sido asumidos por Cartagena), erogaba su parte de gastos derivados del patronato y remitía a Cartagena lo correspondiente a las remesas para la Corona, los ingresos para defensa y los excedentes de la caja. Este sistema se trastornó en primer lugar con el movimiento juntista y, posteriormente, con la separación de Cundinamarca.

${ }^{15}$ Eduardo Posada (comp.), Congreso de las Provincias Unidas 1814-1816 (Bogotá 1988).

${ }^{16}$ El circuito se podría observar de la siguiente manera: Antioquia produce el oro y lo lleva a Santafé para obtener moneda con la cual desarrollar el comercio externo en Cartagena y el interno con Pamplona y Tunja, productores de manufacturas de consumo local popular, que a su vez son llevadas a las zonas mineras para intercambiar por oro en las minas. Ver María Teresa Uribe/Jesús María Álvarez, Poderes y regiones: problemas en la constitución de la nación colombiana, 1810-1850 (Medellín 1987). 
Una las primeras preguntas que surgieron en torno a lo fiscal era si existía algún componente de ingresos que correspondiese al conjunto de las provincias y que, por tanto, debiese ser distribuido entre ellas interrogante que, además, tiene su equivalente en el componente de gastos. En este punto resulta particularmente importante la Casa de la Moneda de Santafé: el gobierno de la Unión la reclamó para sí, pero Cundinamarca no la cedió. En la perspectiva de esta provincia, la noexistencia de los caudales que componían el tesoro público (conjunto del Virreinato) significaba que sólo sería responsable de las erogaciones en la proporción equivalente de sus ingresos. El gobierno de la Unión sostuvo que, mientras no dispusiera de recursos cada provincia, debía sufragar los costos de sus representantes.

Aun cuando se había declarado no modificar la estructura impositiva en la práctica del recaudo, desaparecieron las contribuciones que dependían directamente de la Corona, como las de compra de títulos nobiliarios, penas de cámara, secretaría del Consejo de Indias y comisos del Supremo Consejo. El impacto más fuerte fue sin duda en la disposición de recursos por parte de las cajas matrices. En la caja de Santafé (Cundinamarca), la reducción de los ingresos era superior al $50 \%$ : mientras en 1805 a la caja ingresaron 1.586 .385 pesos reales y en 1807 entraron 1.109 .661 pesos, en 1811 se recibieron apenas 413.217 y en 1812 se llegó a 418.127 pesos. ${ }^{17}$

Los ingresos por concepto de impuestos en la caja de Santafé estuvieron concentrados en alcabala y salinas, que en conjunto aportaron cerca del $25 \%$ de las entradas de la caja; la Casa de la Moneda y la consolidación de vales reales aportaron alternativamente cerca del $30 \%$ a la caja. A la disminución proveniente de la caída en la remisión de las otras cajas hay que sumar la caída en los recaudos del estanco de tabaco. Aun cuando es presumible que algunos recursos ingresaran por este concepto, en los registros no figura el rubro de tabaco, que en 1805 había aportado 106.000 pesos y 53.000 en $1807 .{ }^{18}$ El caso del

${ }_{17}$ Ver Fernando Barriga del Diestro, Finanzas de nuestra primera independencia. Apuntes económicos, financieros y numismáticos (Bogotá 1998); y Archivo General de la Nación, Bogotá (en adelante AGN), Archivo anexo 1, Real Hacienda, tomo 31, año 1814, f. 147. Según esta última fuente en 1813 se registran gastos por 553.474 pesos y en 1814 se asientan en el libro manual 322.034 pesos.

18 AGN, Archivo anexo 1, Real Hacienda, tomo 31, año 1813, f. 785. Resulta curioso observar en los documentos que aunque no existe ingreso por concepto de tabaco hay pagos de sueldos a los empleados de esa renta. 
tabaco puede ser un botón de muestra de las complicaciones en materia económica y de hacienda: en las zonas en las que se mantuvo el estanco (es el caso de Cundinamarca) se requerían recursos para poder realizar la compra de la cosecha de tabaco y luego agenciar su venta tanto externa como interna. Lo exiguo del erario no permitía destinar suficientes recursos a la compra de tabaco y menos aún a promover su cultivo. De otra parte, para lograr la exportación debía atravesar los territorios de la Unión, que por decisión de Cundinamarca para asuntos comerciales operaba como un país extranjero. Por su parte, en el componente de gastos el $75 \%$ se aplicaba a dos grupos: burocracia y milicias, pese a que sus valores no se acercaban a los realizados en el periodo colonial.

La geografía política aquí comentada dio lugar a múltiples frentes de batalla. De una parte, Cartagena se vio compelida a confrontar a los realistas de Santa Marta, situación bastante difícil, dado los exiguos recursos con que contaba la provincia. A la provincia de Popayán la enfrentaron Cundinamarca y la liga de ciudades conformada por Cali, Buga y Cartago. La confrontación armada entre el gobierno de la Unión y Cundinamarca comprometió a esta provincia y a las de Tunja y Casanare. Este último enfrentamiento terminó a finales de 1814 cuando Bolívar al mando del Ejército de la Unión sometió a Cundinamarca.

Ante la disminución de los ingresos, el financiamiento de la guerra se hacía más penoso para las zonas en conflicto. En 1812 el gobernador de Cartagena solicitó al gobierno de las Provincias Unidas que los gastos de las tropas que debían hacer tránsito por la provincia debían estar garantizados desde el inicio de la expedición para que no corrieran a cargo de los exiguos recursos de erario provincial y menos resultar gravosos para la población. ${ }^{19}$

Buena parte de la financiación de la guerra en Cartagena y en Santafé tuvo como fuente la moneda. En Cartagena se creó papel moneda

${ }^{19}$ Carta de Gabriel Torres, fechada en Cartagena en 12 de diciembre de 1816. AGN, Archivo anexo, Guerra y Marina, tomo 145, fs. 76-82. "Excelentísimo Señor: En Todos los distritos de la Provincia y principalmente en aquellos que están sus pueblos situados en las direcciones principales de esta plaza a lo interior del Reino, como son los de Mahates y Barranca del Rey hasta Mompox, los fondos que producen los ramos de Sisa y Alcabalas se han agotado enteramente, habiéndose empleado por los Jueces respectivos, a consecuencia de Superior disposición de Vuestra Excelencia y ordenes de este Gobierno, en las atenciones que ha producido el Real Servicio en tránsito de tropas y demás comisiones, después de haber apurado por su parte cuantos recursos extraordinarios les ha sugerido su celo y buenos deseos de que aquel no sufriese el menor atraso." 
y se acuñaron monedas de cobre, mientras que en Santafé se contó con el respaldo de la Casa de la Moneda. ${ }^{20}$ La otra fuente correspondió a empréstitos, voluntarios unos y forzosos otros, que en la mayoría de los casos se solicitaron para expediciones específicas. ${ }^{21}$ En Cartagena para 1814 se registra un gasto militar equivalente al $75 \%$ del total de gastos en la caja, que mantiene dos ingresos importantes: aduanas y tabaco, que en conjunto aportan cerca del $50 \%$ de los ingresos de la Caja. ${ }^{22}$ En esta provincia, también fue fuente de ingresos la confiscación de las propiedades de españoles adeptos a la causa realista.

A finales de 1815 el Gobierno de la Unión, aduciendo las necesidades de la guerra, decretó en calidad de subsidio

“[...] y por una sola vez, para los gastos de la defensa común, una contribución en razón de las facultades de todos los ciudadanos, que no bajará de cuatro reales ni excederá de quinientos pesos". ${ }^{23}$

Allí quedaron comprendidos toda especie de corporaciones e individuos que contaran con recursos (mínimo de cincuenta pesos). Esta contribución ofrece un elemento interesante porque para poderla ejecutar era preciso determinar el monto de la renta que sería sujeto de gravamen, es decir, implicó una reflexión similar a la del establecimiento de un impuesto directo en la medida que era preciso definir qué bienes y capitales ingresaban en la renta gravable. Esta experiencia impositiva era complementada con el impuesto a las herencias,

20 Óscar Rodríguez Salazar, "La moneda como forma de financiar y dar legitimidad al naciente Estado neogranadino 1750-1821": II Congreso de Historiadores económicos latinoamericanos CLADHE (México, D.F. 2010).

${ }^{21}$ Uno de los créditos más conocidos es el que solicitó Cundinamarca para financiar la expedición al sur, con el fin de expulsar los españoles de la provincia de Popayán. Para este empréstito se creó una comisión que debía establecer los sujetos del empréstito y realizar el recaudo. Por ello, dentro de un conjunto de sectores económicos se hizo la lista de las personas con el aporte correspondiente. Carta de Pedro Groot a Joaquín Vezga, comisionado en Santa Fé para el empréstito, fechada en enero 20 de 1814: AGN, Colonia, Miscelánea, rollo 81, año 1813. No obstante, la estrategia no dio buenos resultados. El crédito estimado era de 300.000 pesos que costaría la campaña del sur, pero no se recolectaron totalmente; a la campaña finalmente se destinaron 110.171 pesos, pero del crédito también se debía rembolsar una transferencia que hizo la casa de moneda, otra que se sacó de la tesorería de diezmos y 40.000 pesos que se aportaron para la siembra de tabaco. Aun así, en marzo de 1814 aun faltaban recursos. AGN, Archivo anexo 1, Real Hacienda, tomo 31, año 1814, fs. 147r-190r.

22 Barriga, Finanzas de nuestra primera independencia (nota 17), p. 73-75.

${ }^{23}$ Posada, Congreso de las Provincias Unidas (nota 15), tomo II, p. 203. 
establecido por el carácter continuo que requieren las finanzas públicas y que poseen las herencias.

Los problemas organizativos también tuvieron su cuota de contribución. El conflicto entre peninsulares y criollos, más fuerte en algunas regiones que en otras, tuvo como uno de sus escenarios la administración pública. La provisión de empleos públicos se constituyó en motivo de conflictos entre facciones, no sólo por las posibilidades de dirigir los destinos de la población, sino también por las ventajas en la administración de recursos. No obstante, el efecto de esta pugna fue el retraso de la administración, la pérdida de recursos y la falta de información. Baste para ilustrar este punto una comunicación de José Gaspar Liaña, contador de Santafé, al presidente de Cundinamarca:

"Excelentísimo señor

23 de diciembre de 1814

El trastorno que ha sido consiguiente a las tropelías ejecutadas en esta oficina por el presidente de la sala de reposición ciudadano Ignacio Herrera, tanto con motivo de la prisión hecha en mi el contador, cuanto por la arbitraria y desconcertada entrega de los caudales y demás enseres del tesoro que le verifico en aquel mismo tiempo; no menos que el que ocasionó la guerra de que felizmente hemos salido ha hecho no poder sentar en los libros las partidas de cargo y data según el orden que debe gobernar en esta oficina principalmente para hacerse el tanteo de fin de año." ${ }^{24}$

Ad portas de iniciarse la reconquista española y una vez incluida Cundinamarca en la Unión, el Congreso de las Provincias Unidas creó la Contaduría General de Hacienda, compuesta por tres contadores generales, tres segundos, un archivero secretario, tres oficiales de pluma y un portero escribiente de la secretaría, y encargada de ordenar el sistema de cuentas de la República. Con esta transformación se inauguró una nueva era en la estructuración administrativa del sistema fiscal, que fue suspendida por la reconquista española.

\section{RECURSOS PARA LA RECONQUISTA ESPAÑOLA Y \\ LA DEFENSA DE LA REPÚBLICA}

Una vez restituido Fernando VII en el trono español, se inició el proceso de reconquista de los territorios americanos. En diciembre de 1815 las tropas reales tomaron la plaza de Cartagena y nombraron un comandante general, a quien la Corona encargó del envío de un inven-

${ }^{24}$ AGN, Archivo anexo 1, Real Hacienda, tomo 30, año 1814, f. 147r. 
tario de todos los empleados con sueldos y los que sean propietarios también de los que por alguna razón estuvieran vinculados a la administración -, de los gastos de la administración general de la guerra, y de ideas de cómo subvenir a estos gastos en la provincia.

Como se ha comentado, a pesar de la avanzada de Cartagena sobre Santa Marta, esta provincia siguió estando bajo el control de los españoles, que habían desplazado la sede de gobierno a Panamá. ${ }^{25}$ El comportamiento de los ingresos y gastos de la caja da una idea de los efectos del conflicto sobre las finanzas públicas. Es interesante destacar que pese a la caída de ingresos siempre quedaba un sobrante líquido, en particular porque no se remuneraban en su totalidad los gastos causados en las rentas administradas, como por ejemplo los estancos de tabaco y aguardiente. Otro interesante componente es que no existieron ingresos por concepto de tributo de indios, dado que en 1812 las Cortes de Cádiz, en un ánimo liberal, habían abolido este impuesto, así como el concierto de indios y las mitas. También hay que anotar que esta caja recibió remesas de otras cajas, pero no de las sufragantes (ver gráfico 5).

\section{Gráfico 5: CARgos y datas de la Caja Real de Santa Marta, 1809-1815}

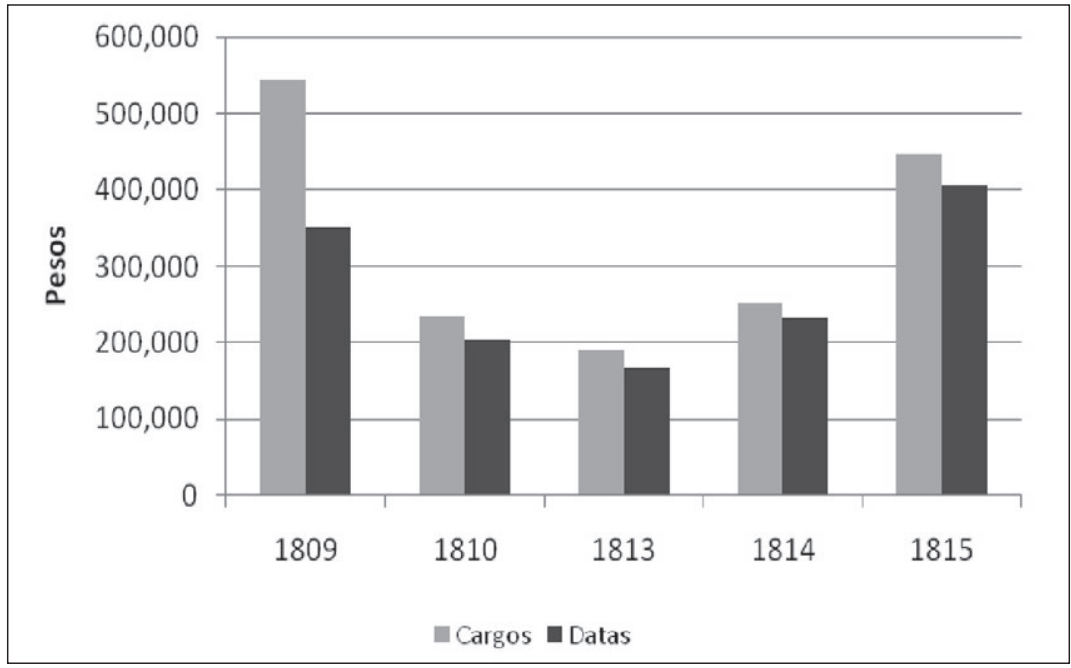

Fuente: AGI, Gobierno, Audiencia de Santafé, legajo 1207.

${ }^{25}$ El virrey Benito Pérez (1810-1813) no pisó el territorio de la Audiencia de Santafé. 
De otra parte, como era de esperarse, un elemento central del gasto lo constituía el militar, pero también resulta fundamental el pago de pensiones generales. La participación de estos rubros pasó del $32 \%$ en 1809 al $89 \%$ en 1815, pues Santa Marta fue un apoyo fundamental para la expedición que tomó Cartagena.

Una vez ocupada la plaza de Cartagena el nuevo virrey, Francisco José de Montalvo, que se había establecido en Riohacha desde su nombramiento en 1813, se trasladó a esta ciudad con el fin de adelantar la recuperación de los territorios en manos de los patriotas. Por su parte, la ocupación militar a cargo del general Pablo Morillo inició su recorrido en la Isla Margarita, y en sucesivas avanzadas sus ejércitos expedicionarios conquistaron los territorios del antiguo Virreinato de Santafé, de manera que a mediados de 1816 Morillo instauró el Gobierno en la ciudad de Santafé, dando lugar a la denominada época del terror.

Una de las principales tareas acometidas por los nuevos gobernantes fue restablecer las cajas reales y aunar recursos para financiar la guerra. El virrey Montalvo permanecía en Cartagena mientras Morillo regía desde Santafé, situación que dio lugar, en más de una ocasión, a dualidades de poder, en especial cuando Morillo decidió establecer un sistema fiscal en la capital del Virreinato. La situación se salvó con una orden de la Corona en que reafirmó la potestad exclusiva del virrey sobre la hacienda y el tesoro.

Igualmente, se presentaron dificultades administrativas de diverso orden, como en el caso de Popayán, que si bien un buen tiempo estuvo en manos de los realistas pasó durante breve tiempo al control de las fuerzas patriotas, de modo que la confección de cuentas y la disposición efectiva de los recursos constituyó una fuente de confusión y pérdida de recursos:

\footnotetext{
„Habiéndoseme hecho por don Manuel del Campo y Larraondo y don José Gabriel de León la entrega (que a fuerza de instancias se concluyó la diligencia a fines de noviembre del año inmediatamente pasado, habiendo tomado posesión de mi empleo en mayo) he pedido se me pongan de manifiesto todos los libros respectivos, y se ha dado por razón, que no se han formado los de los años de 16 y 17 y el de los meses primeros de 18 hasta mi entrada, gobernándose por cuadernos provinciales que tampoco se me han entregado; y se me dice existen en la habitación de don José Gabriel de León. Pidiendo los del año de 14, me han expresado haberlos llevado a Quito el capitán de Dragones don Ramón Vélez, sin haberlos reclamado en todo el tiempo que disfrutamos de tranquilidad. Este defecto, y de otros muchos de esta oficina me impiden cumplir como debo, y me sujetan a estar indagando noticias, cuando se trata
} 
de alguna partida de aquellos años, o se presenta alguna duda. Las cuentas que son de Car[ta]go de los mencionados Campo y León, y comprenden desde el año de 1810 inclusive hasta el 23 de mayo de 1818, lejos de ver que traten de su rendición, hallo que muchos documentos respectivos a ellas ruedan sin orden por esta oficina". ${ }^{26}$

No obstante, los frutos de esta labor se empezaron a ver en 1818 , cuando el total de los ingresos de la caja de Cartagena alcanzó un equivalente al $65 \%$ de lo recaudado en 1809. Dado el carácter de guerra de la empresa conquistadora española, el gasto de la plaza era mayoritariamente en sueldos y equipamiento militar (ver gráfico 6).

GrÁFICO 6: PARTICIPACIÓN DE LOS RAMOS DE ADUANAS Y SITUADOS EN EL INGRESO Y PARTICIPACIÓN DEL GASTO MILITAR EN EL TOTAL DE GASTO (PORCENTAJE)

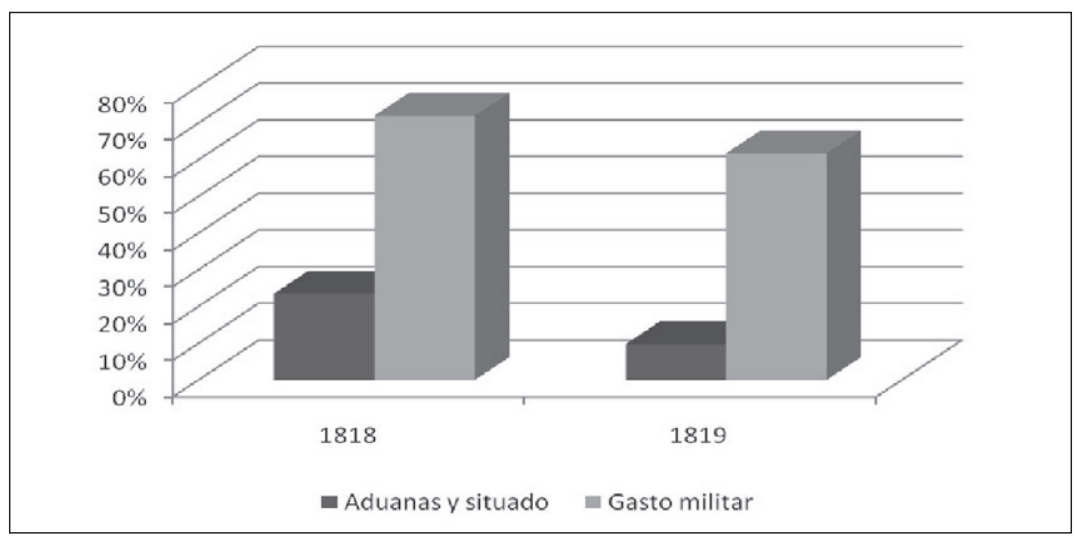

Fuente: Cálculos con base en AGI, Gobierno, Audiencia de Santafé, legajo 1096.

Además del situado y de las remesas de otras cajas, para financiar los gastos de guerra se recurrió a los préstamos (en un valor equivalente a dos veces los ingresos de aduanas) y a donativos. En este último rubro resultan sorprendentes sus elevados valores con respecto a los percibidos por los republicanos antes de la reconquista. ${ }^{27}$

26 AGN, Colonia, Visitas del Cauca, rollo 4, año 1819, fs. 741-745.

${ }^{27}$ Por supuesto resulta difícil diferenciar qué tanto de esos donativos corresponde a la adhesión política y qué tanto al miedo. En la Gazeta Ministerial del N. Reyno de Granada, la Gazeta de Santafé de Bogotá y la Gazeta Real de Cartagena se encuentra la lista de personas con sus donativos. Tanto el gobierno republicano como el realista utilizaron la difusión de los donativos como un mecanismo de propaganda. 
Por su parte, la resistencia republicana se mantuvo hasta 1816 , momento en el cual se rindió a la represión española. Aun cuando había focos de resistencia desde la llegada de Morillo, fue en 1819 cuando se inició la campaña libertadora que duró hasta 1821 cuando los españoles fueron expulsados del territorio de la antigua Audiencia de Santafé. Además de los aportes libres y forzosos de la población que vivía en los caminos por los que pasaban los ejércitos, esta campaña libertadora contó con recursos de crédito. En el Congreso de Angostura (1819) los republicanos tenían como una de sus preocupaciones la obtención de crédito externo, que también estuvo acompañado del interés de predisponer a la opinión pública inglesa a favor del proceso de independencia. Los primeros créditos fueron contratados por un agente en Venezuela, los cuales contribuyeron a traer armamento y también soldados ingleses. El efecto de estos ingresos se vería con posterioridad a 1821, cuando se organizó la nueva República y se debieron cumplir las obligaciones contraídas, para cuyo pago hubo que pignorar algunas rentas. ${ }^{28}$

Con la realización del Congreso de Cúcuta y la creación de la Constitución de 1821, en cuyo primer artículo se afirma que "[1]as Repúblicas de Venezuela y la Nueva Granada quedan desde este día reunidas en una sola, bajo el título glorioso de la República de Colombia", se inició el camino independiente de la Nueva Granada. En términos de organización fiscal se creó la Secretaría de Hacienda y se llevó a cabo una serie de reformas que manifestaron la intención de conformar una república imbuida del pensamiento liberal. Para este efecto, se procedió a eliminar algunos de los impuestos que pesaban sobre las actividades económicas, como sisa, alcabala sobre bienes muebles, el estanco de naipes, el estanco de aguardiente - que fue sustituido por derechos de impuesto sobre la destilación y pequeñas ventas. De otra parte, se abolió el tributo indígena, la mesada, las anatas eclesiásticas, el diezmo, las mitas minera y agraria, y desaparecieron en razón del nuevo régimen político todos aquellos cobros coloniales como las penas de cámara, la compra de títulos, la venalidad de los cargos públicos, etc.

Sin embargo, es preciso tener en cuenta que algunas de estas medidas fueron revocadas, unas más pronto que otras, en tanto la campaña

${ }^{28}$ Decsi Arévalo/Óscar Rodríguez Salazar, Gremios, reformas tributarias y administración de impuestos (Bogotá 2001), p. 43. 
libertadora seguía en las provincias del sur y se requerían ingentes recursos para defender la autonomía política. Otra medida rápidamente derogada fue el establecimiento del impuesto directo, que había sido promovido desde principios de siglo, aún bajo la dominación española. La imposibilidad de un cobro justo, derivada de la inexistencia de un catastro, echó por tierra esa pretensión transformadora del sistema impositivo.

En las cifras presentadas en 1822, los recursos de alcabalas, novenos al Estado, salinas, sobrantes de casa de moneda y los préstamos constituyen los más altos aportes a la hacienda. El registro presentado por la tesorería general muestra una estructura similar a la existente en tiempos coloniales, excepción hecha de los impuestos estamentales totalmente desaparecidos, y deja en evidencia la continuidad de los impuestos que pesaban sobre las actividades económicas. Desde la perspectiva del gasto el mayor rubro lo ocupó el militar, 55\%, mientras que los pagos por empréstitos ocupaban cerca del $8 \%$ del gasto.

\section{Conclusiones}

La estructura fiscal colonial, erigida para garantizar la transferencia del excedente económico de las colonias hacia la metrópoli y el sostenimiento del Estado colonial, contenía un conjunto de gravámenes tanto por su condición de sociedad estamental como por la explotación de aquellos recursos producidos en las colonias que pudieran dar lugar a la apropiación de una parte del producto. A finales del siglo XVIII, si bien estaban formuladas las políticas "liberales" de los Borbones tendientes a mejorar los niveles de producción de las colonias, su puesta en operación no fue posible, en particular porque chocó con los intereses de los comerciantes españoles y por las condiciones de guerra que demandaban grandes recursos para atender la defensa de las posesiones españolas en ultramar. Por su lado, la reconquista española, pese a las experiencias de liberalismo generadas por las Cortes de Cádiz, adoptó la misma posición como en el periodo anterior a 1810 y buscó restituir el poder de la Corona, incluyendo la estructura fiscal.

Para procurar esa fuga del excedente económico, la organización fiscal colonial se hizo a través de un sistema de cajas reales, ligado a la jerarquización de las ciudades, villas, pueblos, etc. Este sistema de 
transferencias fiscales estuvo marcado por las formas de funcionamiento de la dominación colonial. De una parte se trataba de las transferencias hacia la Corona y de otro hacia las ciudades en las que se establecieron las principales funciones de Estado: Cartagena, hacia donde se dirigían los ingresos que financiaban la defensa, y Santafé, en donde residía el poder político, el eclesiástico y la administración virreinal.

La erosión de este sistema durante el periodo de independencia es la transformación más importante en materia fiscal. Con el esquema de dominación colonial adelantado por España, en el que el poder residía por fuera del campo territorial de la colonia, no es posible generar un elemento de unidad territorial al margen de la dominación. De ahí que al producirse la separación de España no existiera una élite o un grupo social con capacidad hegemónica para pensarse como nación. Sí existía un conjunto de élites locales con poder económico que propendían por que su región ascendiera en la escala jerárquica de las ciudades, circunstancia que tenía efectos fiscales.

Tal componente estructural incide de manera directa sobre los resultados fiscales en las zonas que abandonaron la Regencia y luego declararon la independencia. Varios elementos se podrían destacar: En primer lugar la rápida variación en la selección de la forma de gobierno inhibió un cambio en la estructura impositiva. Si en el periodo inicial de la independencia se mantuvo la adhesión a la Corona española, el sistema de transferencias de recursos no se abolió, sino que simplemente se suspendió durante el tiempo en que el rey fue prisionero. La separación de la Corona española significó la organización de un gobierno propio, y en consecuencia los recursos fiscales debieron ser concebidos no con un esquema de apropiación de excedente sino de mantenimiento del Estado en el territorio.

Esta consideración da lugar a la dualidad que se observa en los procesos de liberación nacional en las economías precapitalistas. Por un lado, se quería suprimir ese sistema fiscal porque había un pasado de movilización en contra de los impuestos - en la Nueva Granada fue el movimiento comunero -, y es percibido como un obstáculo al progreso económico. Por otro lado, se necesitaban recursos para sostener el Estado y la situación de guerra; además, no se cuenta con la capacidad organizativa y técnica para renovar la estructura fiscal.

Si bien desde finales de la colonia y durante el periodo independentista se escuchaban voces que propendían por construir una econo- 
mía libre y una sociedad con autonomía y amplia participación política, en aras de garantizar el progreso económico y social, los resultados no condujeron al cumplimiento de ese deseo. En términos impositivos se esperaba la supresión de las cargas que pesaban sobre la actividad económica y, en algunos casos, se proclamó su sustitución por impuestos directos. Lo que se produjo, por el contrario, fue la continuidad de la estructura fiscal colonial con el fin de mantener la autonomía política.

En segundo lugar se encuentra el tema de la territorialidad política y fiscal. La primera dificultad para establecer un Congreso de todas las provincias fue la oposición de Cartagena a que Santafé se proclamara depositaria del gobierno central. Esta situación exhibe la competencia regional creada en el periodo colonial, pero también la ambivalencia entre la autonomía y la asociación. Es notorio que en las diferentes provincias se reconoció el territorio de la Audiencia de Santafé como una unidad, pero a su vez se rechazó a que una provincia o una ciudad tomara el control político-administrativo de todo ese territorio. Esta circunstancia se refleja de manera directa en el sistema fiscal toda vez que rompió con la jerarquía entre las cajas reales establecida en la colonia y convirtió en recursos provinciales los impuestos recolectados en la zona, pero a su vez le impuso la ejecución de gasto que previamente habían sido realizados por otras unidades administrativas.

Por último, surge el tema de cómo considerar la unidad de las provincias. Aun cuando, como se ha señalado, territorialmente las provincias se reconocen formando un conjunto, esta característica no es suficiente para definir una forma de gobierno y, en consecuencia, un sistema fiscal. Las preguntas sobre qué es aquello que los hace una unidad política terminado el régimen colonial y cuáles serían aquellos ingresos que podrían considerarse del conjunto, no tienen respuesta en el momento. 